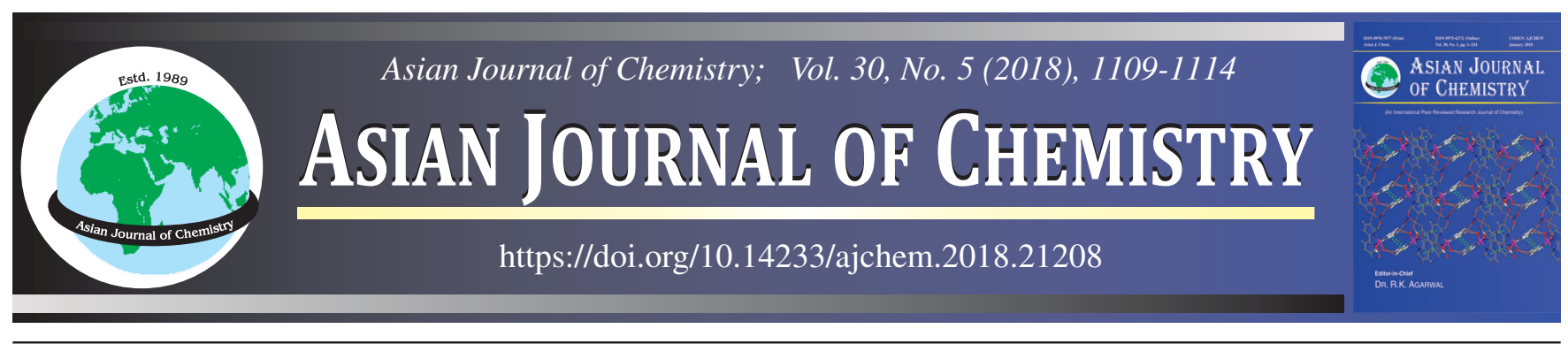

\title{
Occurrence and Distribution of Veterinary Residues in Aquatic Environments near Livestock and Poultry Farms in Zhejiang Province, China
}

\author{
Jianmei Wang ${ }^{1}$, Huizhen Wu ${ }^{2}$, Mingrong Qian ${ }^{1, *}$, Junwei $\mathrm{MA}^{3}$, Hu Zhang ${ }^{1}$ and Hua Yang ${ }^{1, *}$
}

${ }^{1}$ Institute of Quality and Standard for Agro-Products, Zhejiang Academy of Agricultural Sciences, MOA Key Laboratory for Pesticide Residue Detection, Shiqiao Road 198\#, Hangzhou 310021, P.R. China

${ }^{2}$ College of Biology and Environmental Engineering, Zhejiang Shuren University, Shuren Street 8\#, Hangzhou 310015, P.R. China

${ }^{3}$ Environmental Resources and Soil Fertilizer Institute, Zhejiang Academy of Agricultural Sciences, Shiqiao Road 198\#, Hangzhou 310021, P.R. China

*Corresponding authors: Fax: +86 571 86401834, Tel: +86 571 86404005; E-mail: qianmr@mail.zaas.ac.cn; yanghua@mail.zaas.ac.cn

Five categories of antibiotics viz., nineteen fluoroquinolones, sixteen sulfonamides, four tetracyclines, three chloramphenicols, four nitroimidazoles and three of their metabolites were measured in 72 water samples from the river near the livestock and poultry farms in Zhejiang province of China. $48.6 \%$ water sample was positive with at least one drug residue. The detection frequency ranged from $8.3 \%$ for fluoroquinolones to $37.5 \%$ for chloramphenicols. For all the target veterinary drugs, florfenicol had the highest occurrence of $31.9 \%$ with the mean concentration of $484.3 \mathrm{ng} \mathrm{L}^{-1}$. Based on the calculation of hazard quotients, the risk to the aquatic organisms was evaluated and it was demonstrated that the occurrence of sulfamethoxazole, sulfamonomethoxine and florfenicol might pose a risk to aquatic organisms in some study areas.

Keywords: Veterinary drugs, Livestock and poultry farm, LC-MS/MS, Risk assessment.

ᄂ _ - - - - - - - - - - - - - - - - - - - - - - - - - - - -

\section{INTRODUCTION}

Veterinary drugs are chemical compounds which are used to prevent or treat infections and diseases in animals. Veterinary drugs such as antibiotics are used in livestock either to prevent the spread of infection or as growth promoters [1]. In general, the animals adsorb these antibiotics poorly, with approximately $30-90 \%$ of the parent compounds being excreted in urine or feces [2]. Antibiotics used in animal agriculture can enter the aquatic environment directly via discharge [3] or indirectly through the surface runoff of soil to where livestock manure had been applied [4]. Previous studies have shown that livestock manure may act as a non-specific source of antibiotic residues in aquatic environments [5].

Antibiotic residues in aquatic environments may stimulate the spread of bacterial antibiotic resistance [6]. Various veterinary drugs, particularly antibiotics have been frequently detected in sediments [7-9] and surface water [7,10-14], as well as in drinking water [15]. The types and concentrations of veterinary drugs detected in surface waters varied internationally because of different patterns of drug use and consumption. For example, in Spain, decoquinate and sulfonamides were the drugs most frequently detected [11], while macrolides were dominant in urban rivers in Japan [16]. In China, sulfonamides were also the dominant antibiotics found in the water of Baiyangdian lake [17], Huangpu river [18] and Haihe river [10]. Tetracyclines were present in high levels in the Wangyang river [19]. Longterm exposure to antimicrobial agents in aquatic environments imposes a threat on aquatic organisms $[20,21]$ and accelerates the development of antibiotic-resistant microorganisms. Once antibiotic-resistant microorganisms appear in the environment, they may enlarge the resistance community through the transfer of corresponding antibiotic resistance genes among microbial populations in different environmental systems $[6,22]$. It is important to consider the ecological exposure risk of antibiotics at low levels.

Many studies [11,23] have examined the levels of antibiotics in surface water and also have investigated veterinary drug concentrations in waters proximal to livestock and poultry farms. The aim of this study was to investigate the occurrence of veterinary drugs in aquatic environments near livestock and poultry farms in Zhejiang Province of China. Specifically, we focused on sulfonamides, tetracyclines, fluoroquinolones, chloramphenicols, nitroimidazoles and their metabolites, which are the most common antimicrobials used for livestock agriculture in China though some of them have already been banned in animal 
culture. The potential harmful effects of veterinary drugs residue on the aquatic ecosystem is also evaluated in order to provide a basis for evaluating conventional livestock and poultry farm waste treatment in China.

\section{EXPERIMENTAL}

Target standards (Table-1) and internal standard were purchased from Dr. Ehrenstorfer GmbH (Germany), Witega (Germany) or Toronto Research Chemicals (Canada). Methanol of HPLC grade was purchased from Merck (Germany). Disodium ethylenediamine tetraacetate ( $\left.\mathrm{Na}_{2} \mathrm{EDTA}\right)$, citric acid and sodium citrate were of analytical grade and obtained from Huadong Medicine Corporation (China). Oasis HLB cartridges (6 mL, $200 \mathrm{mg}$ ) were supplied by Waters (USA). Purified water was prepared by using a Milli-Q water purification system (Millipore).

Sampling sites and sample collections: A total of 72 water samples were collected from rivers near livestock and poultry farms ( 8 cattle, 42 pig and 5 chicken farms) in Zhejiang Province. Sampling sites were near to 15 farms in Hangzhou (HZ1), 5 farms in Shaoxing (SX), 8 farms in Ningbo (NB), 7 farms in Jinghua $(\mathrm{JH}), 15$ farms in Jiaxing $(\mathrm{JX})$ and 5 farms in Huzhou (HZ2). Detailed sampling site information is shown in Fig. 1. For some rivers, the sites in which were marked as No. 1, 2, 4, 8, 9, 10, 11, 12, 23, 24, 25, 26, 27, 29, 30, 47 and 52 in Fig.1, one sample was collected near the drain outlet of the farm, and another was collected 2-3 km upriver. For other small tributaries, sample collection was only performed at the site near the farm drain outlet. All the samples were collected between March and May 2013 prior to the flood season. Water samples ( $2 \mathrm{~L}$ ) were collected from $0-0.5 \mathrm{~m}$ below the surface using a stainless steel bucket and stored at $-20{ }^{\circ} \mathrm{C}$ in amber glass bottles.

Sample extraction: Veterinary residues in the water samples were concentrated using solid-phase extraction with an Oasis HLB cartridge ( $200 \mathrm{mg}, 6 \mathrm{~mL}$ ) following the method described by Xu et al. [24]. For each sample, $100 \mathrm{~mL}$ was filtered through $0.45 \mu \mathrm{m}$ glass fiber filters and added with $0.2 \mathrm{~g} \mathrm{Na}_{2}$ EDTA and $100 \mathrm{ng}$ mixture internal standards. The resulting mixture was then acidified to $\mathrm{pH} 3$ using phosphoric acid. Samples were loaded into cartridges preconditioned with $5 \mathrm{~mL}$ methanol, $10 \mathrm{~mL}$ water and $6 \mathrm{~mL} \mathrm{Na}_{2}$ EDTA $\left(10 \mathrm{mmol} \mathrm{L}^{-1}, \mathrm{pH}=3\right)$. The flow rate was $5-10 \mathrm{~mL} \mathrm{~min}^{-1}$. The cartridges were further washed with $10 \mathrm{~mL} \mathrm{Na} \mathrm{NDDT}_{2}$ and the target compounds were eluted with $10 \mathrm{~mL}$ methanol with $5 \%$ ammonia solution (v/v). After the eluate was completely evaporated with nitrogen gas at $40^{\circ} \mathrm{C}$, the residue was dissolved in $1 \mathrm{~mL}$ methanol:water $(1: 1, \mathrm{v} / \mathrm{v})$. The solution was then filtered through a $0.22 \mu \mathrm{m}$ Teflon filter for HPLC-MS/MS analysis.

HPLC-MS/MS analysis: Sample separation was performed on a Luna C18 column $(2.0 \mathrm{~mm} \times 150 \mathrm{~mm}, 5 \mu \mathrm{m})$ (Phenomenex, USA) and detected with a TSQ Quantum Discovery mass spectrometer system (Thermo Fisher Scientific, USA). The flow rate of HPLC system was $0.25 \mathrm{~mL} \mathrm{~min}^{-1}$ and the injection volume was $5 \mu \mathrm{L}$. A different chromatographic separation method was used for different antibiotic groups. The mobile phase consisted of methanol (solvent $\mathrm{A}$ ) and $2 \mathrm{mmol} \mathrm{L}^{-1}$ ammonium acetate aqueous with $0.1 \%$ formic acid (solvent B). For fluoroquinolones and nitroimidazoles, the ratio between phases $\mathrm{A}$ and $\mathrm{B}$ was 5 to 5, held for 12 and $6 \mathrm{~min}$, respectively. For tetracyclines, the ratio between phases $\mathrm{A}$ and $\mathrm{B}$ was 4 to 6 , held for 6 min. The sulfonamides were separated in gradient mode using the following process. The initial mobile phase was $20 \% \mathrm{~A}$, and then increased linearly to $90 \%$ in $5 \mathrm{~min}$, held for $11 \mathrm{~min}$, and then decreased back to $20 \%$ for equilibrium. For chloramphenicols, solvent A was methanol, solvent B was water, and the ratio between phases A and B was 8 to 2 for a total of 4 min to achieve separation. For MS detection, all compounds except for chloramphenicols were ionized with electrospray ionization in positive mode and quantified with multiple reaction monitoring. The optimized parameters for multiple reaction monitoring detection of each compound are listed in Table- 1 .

Method validation: All data generated from the analysis were subject to strict quality control procedures. With each set of samples to be analyzed, a solvent blank, a procedure blank and an independent check standard were run in sequence to check for background contamination and system performance. The accuracy of the method used for each type of veterinary drug was evaluated by recovery studies. Recoveries and relative standard deviations (RSDs) were determined for five replicates at three concentrations using spiked blank water samples prior to analysis. The recovery studies were performed using spiked concentrations of 10, 20 and $50 \mathrm{ng} \mathrm{L}^{-1}$. Among the 49 target compounds, the recoveries in the range of $65-138 \%$ were obtained in the spiked water samples (Table-1). The quantification of

TABLE-1

MINIMUM, MAXIMUM, MEAN AND MEDIAN CONCENTRATIONS (ng L L ${ }^{-1}$ IN POSITIVE SAMPLES AND DETECTION FREQUENCIES (\%) OF THE INVESTIGATED ANTIBIOTICS IN ALL WATER SAMPLES

\begin{tabular}{|c|c|c|c|c|c|c|}
\hline Compounds & Abbreviation & $\begin{array}{l}\text { Detection } \\
\text { frequency }\end{array}$ & Minimum & Maximum & Mean & Median \\
\hline Enrofloxacin & ENR & 8.3 & 30.0 & 219.8 & 81.6 & 50.0 \\
\hline Sulfamethazine & SMZ & 19.4 & 30.0 & 3896.1 & 724.3 & 119.9 \\
\hline Sulfachloropyridazine & SCP & 5.6 & 2637.4 & 6093.9 & 4330.7 & 4295.7 \\
\hline Sulfamethoxazole & SMX & 5.6 & 69.9 & 4895.1 & 1326.2 & 169.8 \\
\hline Sulfamonomethoxine & SMM & 20.8 & 50.0 & 19990.0 & 2291.0 & 449.6 \\
\hline Sulfonamides & SAs & 33.3 & 69.9 & 24885.1 & 2797.2 & 514.5 \\
\hline Chloramphenicol & CAP & 2.8 & 40.0 & 69.9 & 54.9 & 54.9 \\
\hline Thiamphenicol & TAP & 9.7 & 79.9 & 1198.8 & 516.6 & 359.6 \\
\hline Florfenicol & $\mathrm{FF}$ & 31.9 & 30.0 & 3396.6 & 484.3 & 199.8 \\
\hline Chloramphenicols & CPs & 37.5 & 30.0 & 4595.4 & 550.6 & 199.8 \\
\hline Oxytetracycline & OTC & 12.5 & 149.9 & 3506.5 & 1454.1 & 599.4 \\
\hline \multirow[t]{2}{*}{ Dimetridazole-2-hydroxy } & HMMNI & 13.9 & 199.8 & 25874.1 & 4125.9 & 1948.1 \\
\hline & All & 48.6 & 40.0 & 30999.0 & 3909.5 & 649.4 \\
\hline
\end{tabular}




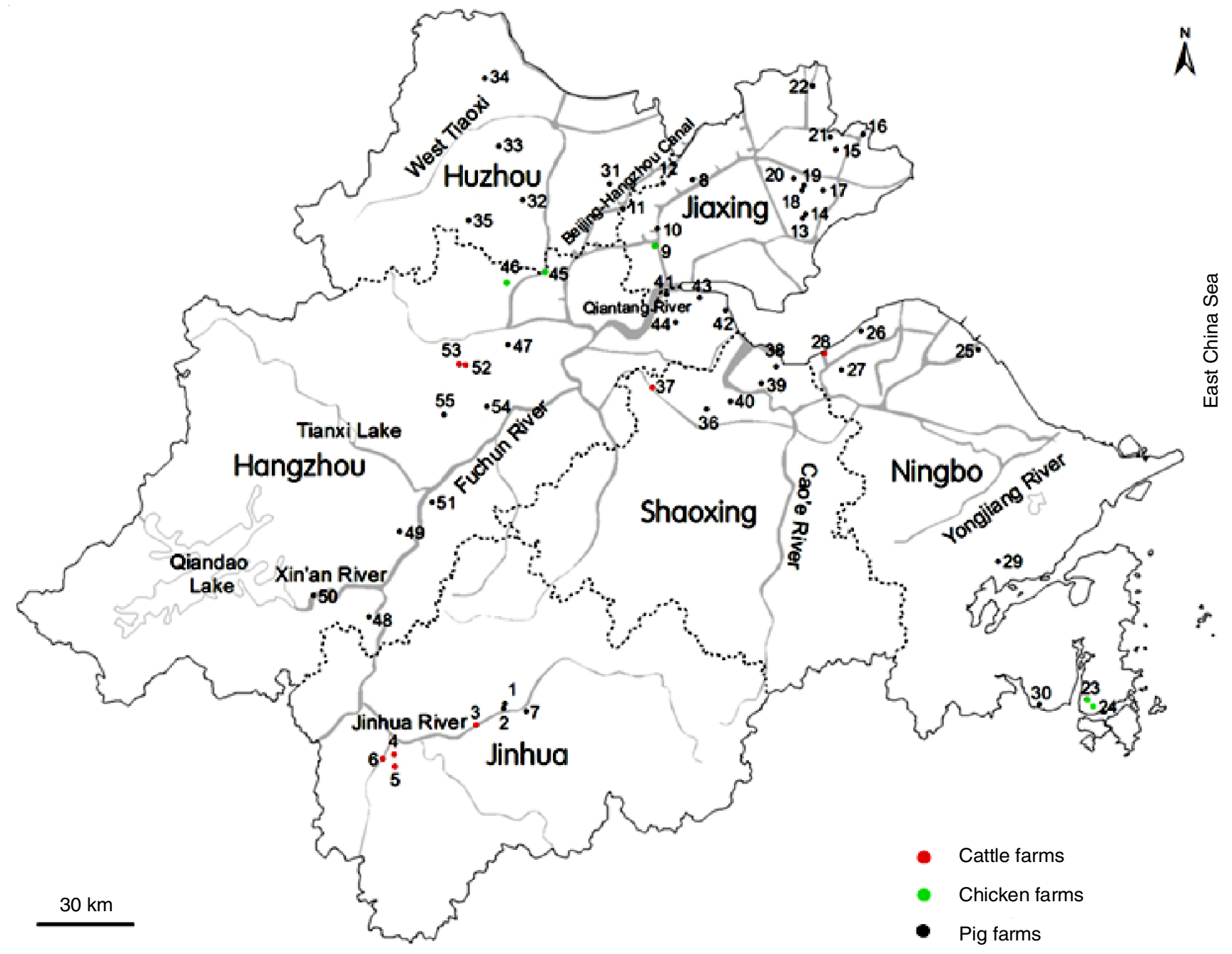

Fig. 1. Graphic representation of the study area

tetracyclines was based on matrix-matched calibration curves. For fluoroquinolones, sulfonamides, chloramphenicols and nitroimidazoles the quantification was based on linear regression calibration curves as well as using the internal standards. Fluoroquinolones and sulfonamides were divided into four groups, respectively, each group using an isotope internal standard (Table-1). Linearity was evaluated using a seven-point linear plot with three replicates and good correlation coefficient $\left(\mathrm{R}^{2}\right.$ $>0.99$ ) were obtained.

The limits of detection (LOD) were calculated in the fortification level of $10 \mathrm{ng} \mathrm{L}^{-1}$ in matrix as signal-to-noise ratios of 3 and the limits of quantification (LOQ) were defined as signalto-noise ratios of 10. The LODs and the LOQs for the selected compounds ranged in 0.05-2.3 and 0.17-7.67 $\mathrm{ng} \mathrm{L}^{-1}$, respectively (Table-1).

Statistical analysis: All statistical analyses on trace metal and antibiotics were performed using the statistical software package SPSS (version 18; SPSS, Inc., Chicago, USA). The differences in antibiotic concentrations in different sampling districts or farm types were analyzed using one-way analysis of variance (ANOVA). Due to the wide range of variation for some of the parameters, the data were transformed to their log 10 values for normalization before ANOVA. Ap-value of less than 0.05 was considered statistically significant.

\section{RESULTS AND DISCUSSION}

Occurrence of target veterinary drug residues in water samples: Among the 49 target compounds, 10 drugs were detected, including 4 sulfonamides (SMZ, SCP, SMM and SMX), 1 fluoroquinolone (ENR), 3 chloramphenicols (CAP, TAP and FF), 1 tetracycline (OTC) and 1 nitroimidazoles (HMMNI). Analyses showed that $48.6 \%$ of water samples were positive with at least one drug. The number of mixed concurrent exposure of antibiotics in one sample was found to reach six. The maximum total concentration detected in single sample in this study was up to $30999.0 \mathrm{ng} \mathrm{L}^{-1}$. Samples who had mixed concurrent exposures of two or more antibiotics accounted for $33.3 \%$. The detection frequencies of 5 veterinary drug categories ranged from $8.3 \%$ for fluoroquinolones to $37.5 \%$ for chloramphenicols. In decreasing order, the sum concentrations of each group were: sulfonamides $\left(67132.8 \mathrm{ng} \mathrm{L}^{-1}\right)>$ nitroimidazoles $\left(41258.7 \mathrm{ng} \mathrm{L}^{-1}\right)>$ chloramphenicols (14865.1 $\left.\mathrm{ng} \mathrm{\textrm {L } ^ { - 1 }}\right)>$ tetracyclines $\left(13086.9 \mathrm{ng} \mathrm{L}^{-1}\right)>$ fluoroquinolones (489.5 $\mathrm{ng} \mathrm{L}^{-1}$ ). It has been reported that some veterinary drugs such as fluoroquinolones and tetracyclines canbe adsorbed strongly by particles or sediment $[8,25]$, and thus, some antibiotic residue may be eliminated through wastewater treatment applied in livestock and poultry farms. While, sulfonamides 
because of its high consumption and high solubility and chemical stability in water and may more easily reach the aquatic environment [26].

Descriptive statistics of the levels of detected veterinary drug residues in the water samples are summarized in Table- 1 . Of the detected compounds, the maximum mean concentration was $4125.9 \mathrm{ng} \mathrm{L}^{-1}$ for HMMNI. Sulfonamides, however, were the primary residue detected in these water samples, with a mean concentration of $2797.2 \mathrm{ng} \mathrm{L}^{-1}$. SMM and SMZ had mean concentrations of 2291.0 and $724.3 \mathrm{ng} \mathrm{L}^{-1}$ with detection frequencies of 20.8 and $19.4 \%$, respectively. Both of the detection frequencies of SCP and SMX were $5.6 \%$. The levels of SMX detected in rivers of this study was higher than that in the Huangpu river (2.2-764.9 $\left.\mathrm{ng} \mathrm{L}^{-1}\right)$ [18], Yangtze estuary (0.3-56.8 $\left.\mathrm{ng} \mathrm{L}^{-1}\right)$ [13], Pearl river estuary (not detect (nd)-37.6 $\mathrm{ng} \mathrm{L^{-1 }}$ ) [7] and the surface water in Beijing (nd-650 ng L $\mathrm{L}^{-1}$ ) [27]. Of the chloramphenicols including CAP, FF and TAP, the fluoroquinolone was the most commonly detected and had a detection frequency of $31.9 \%$ and a mean concentration of $484.3 \mathrm{ng} \mathrm{L}^{-1}$. Compared to the results reported from other studies, the concentration of fluoroquinolone in this study was far higher than that reported in Yangtze estuary ( 0.5-89.5 ng $\mathrm{L}^{-1}$ ) [13] and Huangpu river (nd-241.1 [18] and 6.9-46.6 ng $\left.\mathrm{L}^{-1}\right)$ [12]. Enrofloxacin was detected in six samples and the concentrations ranged from 30.0 to $219.8 \mathrm{ng} \mathrm{L}^{-1}$. The concentrations of enrofloxacin detected in this study (nd-219.8 ng $\mathrm{L}^{-1}$ ) was higher than those previously reported in samples from the surface water in Spain (1.3-118.4 $\left.\mathrm{ng} \mathrm{L}^{-1}\right)$ [11], Haihe river (nd-50.8 ng L ${ }^{-1}$ ) [10], Huangpu river (nd-14.6 ng L ${ }^{-1}$ ) [18], urban surface water in Beijing (nd-28.8 $\mathrm{ng} \mathrm{L}^{-1}$ ) [27] and Yangtze estuary (nd-4.8 $\mathrm{ng} \mathrm{L}^{-1}$ ) [13] in China. HMMN1 and OTC were found with detection frequencies of 13.9 and $12.5 \%$, respectively. The OTC residues in this study was far higher than that data reported in Yangtze estuary (nd-22.5 ng L $\mathrm{L}^{-1}$ ) [13], Huangpu river (nd-219.8 $\mathrm{ng} \mathrm{L}^{-1}$ ) [18], but a bit lower than that in Wangyang river (mean concentration $97433.8 \mathrm{ng}$ $\mathrm{L}^{-1}$ ) [19]. In this study, most of the rivers in which the samples were collected were in small size, most of them are the tributaries. The pollution levels of the target antibiotics in these tributaries aremostly higher than those in large river, which may be due to the lower water flux in tributaries and the intensive livestock farms near the tributaries.

Occurrence of antibiotics in the sampling districts: The residue levels of the veterinary drugs varied among areas. Summing all drug residues in each water sample, and according to the concentration range, the six sampling districts were sorted in increasing order and displayed as: HZ2 (nd-379.6 ng L $\left.{ }^{-1}\right)<$ HZ1 (nd-5484.5 ng L $\left.{ }^{-1}\right)<$ JX (nd-6653.3 ng L $\left.{ }^{-1}\right)<$ SX (nd-9050.9 ng L ${ }^{-1}$ ) $<\mathrm{NB}$ (nd-13616.4 $\mathrm{ng} \mathrm{L}^{-1}$ ) $<$ JH (nd$\left.30999.0 \mathrm{ng} \mathrm{L}^{-1}\right)$. According to the mean concentrations in single sample, it was displayed as: HZ2 $\left(249.8 \mathrm{ng} \mathrm{L}^{-1}\right)<\mathrm{HZ1}(1528.5$ $\left.n g \mathrm{~L}^{-1}\right)<\mathrm{JX}\left(1668.3 \mathrm{ng} \mathrm{L}^{-1}\right)<\mathrm{SX}\left(2977.5 \mathrm{ng} \mathrm{L}^{-1}\right)<\mathrm{NB}(3456.5$ $\left.n g \mathrm{~L}^{-1}\right)<\mathrm{JH}\left(11588.4 \mathrm{ng} \mathrm{L}^{-1}\right)$. The concentration of SMZ in JH was significantly $(\mathrm{p}<0.05)$ higher compared with those in $\mathrm{JX}$. The high residue level sat JH may berelated to the local farms in small scale and running with intensive breeding as well as rough waste treatment or direct waste discharge without proper handling.
Among the 17 rivers in which water samples were collected both at upstream and proximal sites (34 total samples), the residue detection rate were both $20.6 \%$ in upstream and proximal sites samples. There was no significant difference in antibiotic concentration between upstream and proximal sites $(p>0.05)$. FF detection was highest, with rates more than $23 \%$. SMZ had the second highest detection rate at $20.6 \%$. It was shown in Fig. 2, at No. 1, 8, 9, 11 and 12 rivers, fewer and lower drug residues were found upstream compared with corresponding proximalsites. To some extent, it was demonstrated the animal culture produce some veterinary drugs contamination to the surrounding water environment. While, for other instances in Fig. 2, veterinary residues that were detected in upstream water samples were not found or found in lower concentrations in the corresponding proximal water sample. According to our investigation, there was an aquaculture farm near the upstream site of river No. 27. So the several veterinary drugs found in the sample $27 \mathrm{a}$, while not in $27 \mathrm{~b}$ may result from the application of fishery medicine into the aquatic environment. In addition, considering there are a few small villages locating near to the sampling sites and some of the target compounds, such as ENR, NOR, TC, CTC are in human external or internal use, to some extent antibiotic contamination in these rivers may be attributed to the human health care.

Effect of farm type on the residue levels in river: The type, scale and waste treatment of livestock and poultry farms are related with the identity and concentrations of released veterinary drugs into environment. In this part, we used the data from the drain outlet samples to compare the difference, which was speculated to be related with the farm types. As a result, fluoroquinolones were found in the river near cattle and pig farms, while tetracyclines were only found in the river near pig farms, in which OTC was detected with the occurrence of $21.4 \%$ at concentrations up to $3506.5 \mathrm{ng} \mathrm{L}^{-1}$. Sulfonamides, chloramphenicols and nitroimidazoles were detected in the rivers near these three types of farms. Among these three farms types, the detection frequency of nitroimidazoles were similar while the mean concentration varied from $1298.7 \mathrm{ng} \mathrm{L}^{-1}$ near the cattle farms to $5999.4 \mathrm{ng} \mathrm{L}^{-1}$ near the pig farms. The maximum concentration of detected single drug was that of HMMNI at $25874.1 \mathrm{ng} \mathrm{L}^{-1}$ near the pig farms. Chloramphenicols showed with the highest detection frequency of $80.0 \%$ but the lowest mean concentration of $129.9 \mathrm{ng} \mathrm{L}^{-1}$ in the samples adjacent to cattle farms while the highest mean concentration (725.9 $\mathrm{ng} \mathrm{L}^{-1}$ ) and the lowest detection ratio (37.5\%) were observed near the cattle farms and pig farms, respectively. The detection frequencies of sulfonamides among the farm types were in the following order: cattle farm $(38.1 \%)<$ pig farm $(50.0 \%)<$ chicken farm $(60.0 \%)$. Instead, the mean concentration from high to low were chicken farm $\left(123.2 \mathrm{ng} \mathrm{L}^{-1}\right)$, pig farm (2125.4 $\left.\mathrm{ng} \mathrm{L}^{-1}\right)$ and cattle farm (8059.4 $\left.\mathrm{ng} \mathrm{L}^{-1}\right)$. The selected drugs treatment to different animal disease may result in veterinary residue type difference in samples near three farm types. The concentration of SMM near the swine farms compared with those near the cattle farms, the deference was significant $(p<0.05)$. This suggested that antibiotics are less frequently used in cattle than in swine. In further, based on more information of the farm scale, culture density, water 


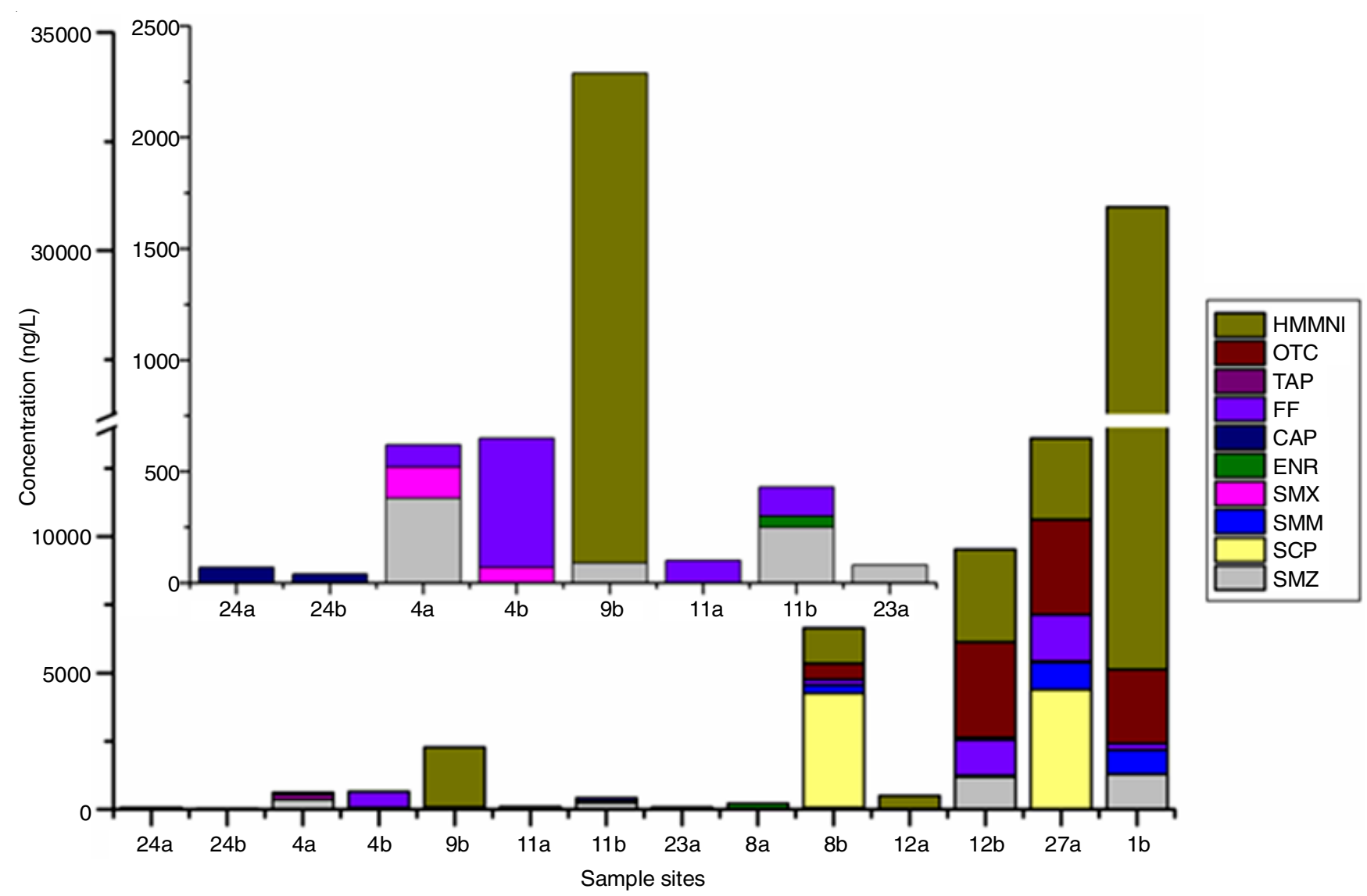

Fig. 2. Drugs detected in upstream (a) and the corresponding sites near the drain outlet of the farm (b)

treatment in farms etc., the related contamination levels in surrounding water environment might be predicted.

Environmental risk assessment: Hazard quotients (HQs) are the ratio between the predicted concentrations (PEC) of a contaminant and its corresponding predicted no-effect concentration (PNEC) [28]. When PNEC values are unavailable, alternative PNECs can be derived by dividing $\mathrm{EC}_{50}(50 \%$ effect concentration)values by an assessment factor of up to 1000 $[28,29]$. To create a worst-case scenario, the maximum measured environmental concentration (MEC) of each drug detected in this study was used instead of PEC, and the corresponding lowest $\mathrm{EC}_{50}$ value found in the literature was used to calculate each hazard quotient (HQ) (Table-2). For SMZ, SCP, TAP and OTC, the maximum concentration was used to calculate HQ values and they were all lower than 1 , which indicated no risk from the presence of these drug residues in the surface waters and no further assessment was required [29]. While for SMM in one sample which collected near a cattle farm, the calculated HQ values were 3.4 and 1.3 for algae and magna, respectively. For SMX, in four samples (three samples were collected near cattle farms and one sample was approximate to a chicken farm) the calculated HQs for algae ranged from 2.3 to 163.3; For FF, a substitute for CAP, in two samples collected near pig farms the calculated HQs for algae were 1.3 and 2.6, respectively. In addition, a sample collected near a cattle farm, the HQs was more than 1 by evaluating either the concentration of SMM or SMX. It was indicated that persistent concentration of these veterinary drugs in rivers near livestock or poultry farm should be monitored and the potential toxicity to environmental biota should be concerned. Additionally, the mode for evaluating combined toxicity of multiple veterinaries to aquatic environment biota had better to be developed to provide more reliable information for risk assessment on real and complicated water samples.

TABLE-2

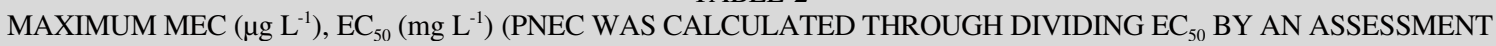
FACTOR OF 1000) AND HAZARD QUOTIENTS OF SOME VETERINARY DRUGS FOR ALGAE, MAGNA AND FISH

\begin{tabular}{ccccc|ccccc}
\hline \multirow{2}{*}{ Compounds } & \multirow{2}{*}{ MEC } & \multicolumn{3}{c|}{ EC $_{50}$} & \multicolumn{3}{c}{ Hazard quotients } \\
\cline { 2 - 7 } & & Algae & Magna & Fish & Algae & Magna & Fish & $<0.04$ \\
SMZ & 3.9 & - & 147.5 & $>100$ & - & 0.03 & {$[30]$} & $<.01$ \\
SCP & 6.1 & - & 177.3 & 535.7 & - & 0.03 & {$[30]$} \\
SMM & 20.0 & 5.9 & 14.9 & $>1000$ & 3.4 & 1.4 & $<0.02$ & {$[20]$} \\
SMX & 4.9 & 0.03 & 25.2 & 562.5 & 163.3 & 0.2 & 0.009 & {$[30-32]$} \\
FF & 3.4 & 1.3 & 337 & - & 2.6 & 0.01 & - & {$[21,33]$} \\
TAP & 1.2 & 38 & - & - & 0.03 & - & - & {$[33]$} \\
OTC & 3.5 & 7.1 & 22.6 & - & 0.5 & 0.2 & - & {$[31,34]$} \\
\hline
\end{tabular}




\section{Conclusion}

This study investigated the occurrence and distribution of veterinary residues in aquatic environments near livestock and poultry farms in Zhejiang Province of China. The profile of veterinary drugs residue released from the animal culture farms into adjacent water environment was analyzed. FF, SMM, SMZ and HMMNI were the main veterinary drugs detected. Thetotal concentrations in single water sample ranged fromnd to $30999.0 \mathrm{ng} \mathrm{L}^{-1}$. Hazard quotients (HQs) calculated using the detectedconcentrationsindicated that SMM, SMX and FF are most likely to pose an environmental risk to algal communities in the study area.

\section{ACKNOWLEDGEMENTS}

This work was supported by the Nature Science Foundation of China (No. 21507114) and State Key Laboratory Breeding Base for Zhejiang Sustainable Pest and Disease Control (2010DS700124-ZZ1602, 2010DS700124-ZM1604).

\section{REFERENCES}

1. X. Pan, Z. Qiang, W. Ben and M. Chen, Chemosphere, 84, 695 (2011); https://doi.org/10.1016/j.chemosphere.2011.03.022.

2. L. Zhao, Y.H. Dong and H. Wang, Sci. Total Environ., 408, 1069 (2010); https://doi.org/10.1016/j.scitotenv.2009.11.014.

3. K. Kummerer, Chemosphere, 75, 417 (2009); https://doi.org/10.1016/j.chemosphere.2008.11.086.

4. J.C. Chee-Sanford, R.I. Mackie, S. Koike, I.G. Krapac, Y.F. Lin, A.C. Yannarell, S. Maxwell and R.I. Aminov, J. Environ. Qual., 38, 1086 (2009); https://doi.org/10.2134/jeq2008.0128.

5. H. Dolliver and S. Gupta, J. Environ. Qual., 37, 1227 (2008); https://doi.org/10.2134/jeq2007.0392.

6. W. Cheng, H. Chen, C. Su and S. Yan, Environ. Int., 61, 1 (2013); https://doi.org/10.1016/j.envint.2013.08.023.

7. X. Liang, B. Chen, X. Nie, Z. Shi, X. Huang and X. Li, Chemosphere, 92, 1410 (2013); https://doi.org/10.1016/j.chemosphere.2013.03.044.

8. L.J. Zhou, G.G. Ying, J.L. Zhao, J.F. Yang, L. Wang, B. Yang and S. Liu, Environ. Pollut., 159, 1877 (2011); https://doi.org/10.1016/j.envpol.2011.03.034.

9. H. Shi, Y. Yang, M. Liu, C. Yan, H. Yue and J. Zhou, Mar. Pollut. Bull., 83, 317 (2014); https://doi.org/10.1016/j.marpolbul.2014.04.034.

10. L. Gao, Y. Shi, W. Li, J. Liu and Y. Cai, J. Environ. Monit., 14, 1248 (2012); https://doi.org/10.1039/c2em10916f.

11. A. Iglesias, C. Nebot, B.I. Vazquez, J.M. Miranda, C.M. Abuin and A. Cepeda, Environ. Sci. Pollut. Res. Int., 21, 2367 (2014); https://doi.org/10.1007/s11356-013-2142-7.

12. L. Jiang, X. Hu, D. Yin, H. Zhang and Z. Yu, Chemosphere, 82, 822 (2011); https://doi.org/10.1016/j.chemosphere.2010.11.028.

13. C. Yan, Y. Yang, J. Zhou, M. Liu, M. Nie, H. Shi and L. Gu, Environ. Pollut., 175, 22 (2013); https://doi.org/10.1016/j.envpol.2012.12.008.
14. H. Chen, X. Li and S. Zhu, Environ. Sci. Pollut. Res. Int., 19, 2381 (2012); https://doi.org/10.1007/s11356-012-0750-2.

15. Z. Ye, H.S. Weinberg and M.T. Meyer, Anal. Chem., 79, 1135 (2007); https://doi.org/10.1021/ac060972a.

16. A. Murata, H. Takada, K. Mutoh, H. Hosoda, A. Harada and N. Nakada, Sci. Total Environ., 409, 5305 (2011); https://doi.org/10.1016/j.scitotenv.2011.09.014.

17. W. Li, Y. Shi, L. Gao, J. Liu and Y. Cai, Chemosphere, 89, 1307 (2012); https://doi.org/10.1016/j.chemosphere.2012.05.079.

18. K. Chen and J.L. Zhou, Chemosphere, 95, 604 (2014); https://doi.org/10.1016/j.chemosphere.2013.09.119.

19. Y. Jiang, M. Li, C. Guo, D. An, J. Xu, Y. Zhang and B. Xi, Chemosphere, 112, 267 (2014); https://doi.org/10.1016/j.chemosphere.2014.04.075.

20. D.J. Huang, J.H. Hou, T.F. Kuo and H.T. Lai, Environ. Toxicol. Pharmacol., 38, 874 (2014); https://doi.org/10.1016/j.etap.2014.09.006.

21. M. Kolodziejska, J. Maszkowska, A. Bialk-Bielinska, S. Steudte, J. Kumirska, P. Stepnowski and S. Stolte, Chemosphere, 92, 1253 (2013); https://doi.org/10.1016/j.chemosphere.2013.04.057.

22. B. Huerta, E. Marti, M. Gros, P. Lopez, M. Pompeo, J. Armengol, D. Barcelo, J.L. Balcazar, S. Rodriguez-Mozaz and R. Marce, Sci. Total Environ., 456-457, 161 (2013); https://doi.org/10.1016/j.scitotenv.2013.03.071.

23. E.R. Campagnolo, K.R. Johnson, A. Karpati, C.S. Rubin, D.W. Kolpin, M.T. Meyer, J.E. Esteban, R.W. Currier, K. Smith, K.M. Thu and M. McGeehin, Sci. Total Environ., 299, 89 (2002); https://doi.org/10.1016/S0048-9697(02)00233-4.

24. W.H. Xu, G. Zhang, S.C. Zou, X.D. Li and Y.C. Liu, Environ. Pollut., 145, 672 (2007); https://doi.org/10.1016/j.envpol.2006.05.038

25. E.M. Golet, A.C. Alder and W. Giger, Environ. Sci. Technol., 36, 3645 (2002); https://doi.org/10.1021/es0256212.

26. Y. Luo, L. Xu, M. Rysz, Y. Wang, H. Zhang and P.J. Alvarez, Environ. Sci. Technol., 45, 1827 (2011); https://doi.org/10.1021/es104009s.

27. W. Li, L. Gao, Y. Shi, J. Liu and Y. Cai, Environ. Sci. Process. Impacts, 17, 1611 (2015); https://doi.org/10.1039/C5EM00216H

28. M.J. Garcia-Galan, S. Gonzalez-Blanco, R. Lopez-Roldan, S. Diaz-Cruz and D. Barcelo, Sci. Total Environ., 437, 403 (2012); https://doi.org/10.1016/j.scitotenv.2012.08.038.

29. A. Ginebreda, I. Munoz, M.L. de Alda, R. Brix, J. Lopez-Doval and D. Barcelo, Environ. Int., 36, 153 (2010); https://doi.org/10.1016/j.envint.2009.10.003.

30. Y. Kim, K. Choi, J. Jung, S. Park, P.G. Kim and J. Park, Environ. Int., 33, 370 (2007); https://doi.org/10.1016/j.envint.2006.11.017.

31. M. Isidori, M. Lavorgna, A. Nardelli, L. Pascarella and A. Parrella, Sci. Total Environ., 346, 87 (2005); https://doi.org/10.1016/j.scitotenv.2004.11.017.

32. B. Ferrari, R. Mons, B. Vollat, B. Fraysse, N. Paxéus, R.L. Giudice, A. Pollio and J. Garric, Environ. Toxicol. Chem., 23, 1344 (2004); https://doi.org/10.1897/03-246.

33. H.-T. Lai, J.-H. Hou, C.-I. Su and C.-L. Chen, Ecotoxicol. Environ. Saf., 72, 329 (2009); https://doi.org/10.1016/j.ecoenv.2008.03.005

34. K. Eguchi, H. Nagase, M. Ozawa, Y.S. Endoh, K. Goto, K. Hirata, K. Miyamoto and H. Yoshimura, Chemosphere, 57, 1733 (2004); https://doi.org/10.1016/j.chemosphere.2004.07.017. 